\title{
LA COHESIÓN NACIONAL A TRAVÉS DE LA PRENSA ESCOLAR DE LOS COLEGIOS DEL EXILIO ESPAÑOL EN LA CIUDAD DE MÉXICO (1939-1960)
}

\section{National cobesion through the school's press of the schools in the Spanish exile in Mexico city (1939-1960)}

\author{
Sandra GARCíA DE FEZ \\ Universitat de València \\ Correo-e: m.sandra.garcia@uv.es
}

Recepción: I de junio de 20I6. Envío a informantes: 24 de noviembre de 2016 Aceptación definitiva: ro de febrero de 2017

Resumen: El proyecto republicano español que llegó al poder en I93I contaba con un fuerte respaldo del mundo cultural. El medio escrito fue el vehículo que se usó para difundir sus reformas. En los círculos políticos y literarios fueron numerosas las publicaciones que vieron la luz de la pluma de literatos consolidados y de los propios testigos. La publicación de prensa perduró durante la Guerra Civil e incluso los barcos que trasladaron a miles de refugiados a México fueron testigos de tres revistas que proclamaban la necesidad de mantenerse unidos al llegar al destino. Esa intención subyacía en los periódicos escolares de los cuatro colegios españoles de la capital mexicana y que permiten rastrear la presencia de España como referente común.

PALABRAS Clave: emigración; España; México; revista escolar; identidad cultural.

AвSTRACT: The Spanish republican project that came into power in I93I relied on a strong support of the cultural world. Written media were used to spread its reforms that it supported. In political and literary circles, numerous publications were released by established writers as well as by the witness of this period. The publication of newspapers went on during the Civil War. Even the boats that 
transfered the refugees to Mexico, had three publications that proclaimed the necessity of staying united after the arrival. This intention was implicit in the school newspapers of the four Spanish schools in the Mexican capital and helped to keep track of Spain's presence as a common referent.

KEY WORDs: emigration; Spain; Mexico; school magazine; cultural identity.

\section{La prensa periódica y la Segunda República española}

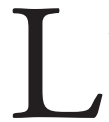

A PRENSA, EN CUALQUIERA DE SUS FORMATOS, tiene como finalidad comunicar y poner en relación y para ello aglutina informaciones en un formato trasladable y reproducible. En el caso de las publicaciones escolares, cuenta con un valor añadido: el pedagógico. Toda palabra escrita por un niño o niña forma parte de su aprendizaje: qué parte de la realidad es seleccionada y tamizada por la visión y la escritura de un autor neófito y cómo plasmarlo en el papel contribuyen enormemente en la formación intelectual y en la capacidad crítica de la persona. Así mismo, lo publicado busca trascender las paredes del centro y acercar al alumnado la sociedad y, a su vez, permitir a ésta asomarse a la vida e inquietudes de la comunidad educativa. Los colegios estudiados tienen la particularidad de ubicarse en México y ser entidades creadas por republicanos españoles emigrados, con el propósito de formar a las nuevas generaciones en un proyecto identitario y político propio, lo que enriquece notablemente el análisis de los periódicos escolares como elemento clave de cohesión nacional.

Estas instituciones continuaron el modelo pedagógico que se diseñó y desarrolló durante la Segunda República, con claras influencias de la Institución Libre de Enseñanza, la escuela freinetista y otras corrientes formativas de principios del siglo xx. Parte del profesorado republicano estudió y vivió las nuevas teorías durante estancias becadas por el Gobierno en otros países europeos ${ }^{1}$. Gracias a las vivencias de otros modos de hacer en educación fuera de España y a la experiencia laboral previa, los alumnos y alumnas de los llamados 'colegios del exilio' recibieron una excelente formación académica y mantuvieron la tradición cultural española y, en parte, el proyecto republicano en el destierro. Las revistas analizadas se constituyeron, de este modo, en un elemento que reforzaba la imagen corporativa del centro, así como su origen e identidad de origen. A su vez, fueron un elemento didáctico perfecto para fortalecer, entre el alumnado de mayor edad, las competencias de comunicación basadas en la lectura y en la escritura, la capacidad analítica de la realidad y la participación en la vida de la escuela y fuera de ella.

En este sentido las instituciones escolares continuaron con una práctica fuertemente arraigada entre los republicanos: la prensa periódica. La difusión de modestas

La labor desarrollada por la Junta de Ampliación de Estudios resultó clave para que pedagogos y pedagogas viajaran fuera de España y conocieran de primera mano las nuevas vías educativas. Para ampliar información consultar MARín ECED, Teresa: «La Pedagogía Europea importada por los becados de la JAE (1907-1937)", Historia de la Educación: Revista Interuniversitaria, Salamanca, 6 (I987), pp. 26I-278. 
LA COHESIÓN NACIONAL A TRAVÉS DE LA PRENSA ESCOLAR DE LOS COLEGIOS DEL EXILIO ESPAÑOL EN LA CIUDAD DE MÉXICO (I939-I960) SANDRA GARCÍA DE FEZ

revistas o escuetos folletos informativos fue una constante en el bando republicano durante la guerra, la dura estancia en campos de concentración e incluso en los barcos que les trasladaron a América², buscando la unidad del colectivo a la vez que recordar y mantener viva la lucha, a pesar de las condiciones de penuria y desamparo en las que se encontraban sus protagonistas.

Un buen número de los españoles y españolas que llegaron a México residieron en la capital, lo que facilitó la puesta en marcha entre i939 y i94I de los cuatro centros que se comparan en este estudio ${ }^{3}$. Dicho análisis arroja interesantes datos sobre lo importante que era para los recién llegados y sus órganos de gobierno mantener entre las generaciones más jóvenes de españoles el legado de la Segunda República y el propósito de reinstaurar la democracia en España y posibilitar, así, el ansiado regreso de los millares de connacionales repartidos por medio mundo. Para conseguir este proyecto, se hacía imprescindible mantener la unidad nacional e ideológica de los asilados y cimentar la legitimidad de los organismos republicanos en el exilio de cara al escaparate internacional.

\section{Los centros educativos del exilio en la Ciudad de México}

Tras el desenlace de la Guerra Civil española en 1939, miles de personas se vieron obligadas a abandonar el país atravesando la frontera natural con Francia por los Pirineos. Entre unas 20.000 y $25.000^{4}$ de ellas pudieron salir de Europa rumbo a México, favorecidas por la política de acogida brindada por el presidente Lázaro Cárdenas y secundada por el Gobierno que dirigías. Cárdenas, perteneciente al Partido de la Revolución Mexicana (PRM), llevó a cabo muchas e importantes reformas en distintos sectores, teniendo gran incidencia las desarrolladas en economía (la nacionalización del petróleo, por ejemplo), en el ámbito social y en el educativo, durante su sexenio (1934-1940). De hecho, su propuesta de una educación socialista permeó, en cierto modo, el funcionamiento de los colegios españoles erigidos bajo su sexenio. También es reconocido el interés mostrado por asuntos internacionales en los que su Gobierno tomaba partido y actuaba en

2 Numerosos fueron los medios escritos durante el conflicto bélico y, en menor medida, en los campos de concentración franceses. No fue diferente en las travesías en barco dirección a México, los cuales contaron con sus propios periódicos. Para consultar las ediciones en facsímil: Serrano Migallón, Fernando (Presentación): Los barcos de la libertad. Diarios de viaje Sinaia, Ipanema y Mexique (mayo-julio 1939), México, El Colegio de México, 2006.

La creación de centros educativos por parte de exiliados republicanos no se limitó a la capital, sino que se instituyeron más colegios en otros estados del país, bajo el Patronato Cervantes. Para saber más sobre estos colegios, consultar: Cruz Orozco, José I.: «El Patronato Cervantes de México y los colegios de provincias en el exilio pedagógico de I939", Historia de la Educación: Revista Interuniversitaria, Salamanca, is (1996), pp. 453-465.

4 No existe un acuerdo tácito sobre el número de exiliados españoles llegados a México, por lo que la cifra más ampliamente consensuada se encuentra entre estas dos cantidades.

5 El mandato de Lázaro Cárdenas del Río abarcó el sexenio de 1934 a 1940. Su Gobierno fue el promotor de la acogida de exiliados republicanos españoles, continuada, con menor intensidad, por el presidente sucesor Manuel Ávila Camacho en la década de los cuarenta. 
consecuencia, como fue el caso de la defensa del Gobierno republicano durante la Guerra Civil española y tras su desenlace.

Si bien el apoyo que el Gobierno mexicano brindó a los españoles exiliados fue un hecho incuestionable, no fue así con otros colectivos de refugiados necesitados también de solidaridad en los mismos años, como ocurrió con los judíos que huían de la Alemania nazi. Dicho colectivo quedó fuera de la política de puertas abiertas ofrecida a los republicanos españoles. Así las cosas, se les restringió de forma muy estricta la entrada al país, pese a encontrarse perseguidos y amenazados, alegándose motivos como la dificultad de asimilarse a las costumbres y cultura de la sociedad mexicana, que no trataban más que ocultar un antisemitismo enraizado entre los mexicanos ${ }^{6}$.

En todo caso, la implicación del presidente Cárdenas con la defensa de la democracia española se inició durante el conflicto bélico. En 1937, instituciones mexicanas y españolas dependientes de los respectivos gobiernos organizaron la primera expedición para trasladar a Morelia a 456 menores que residieron y estudiaron en la Escuela Industrial México-España, sita en dicha localidad del estado de Michoacán. Estos niños y niñas, conocidos como 'Los niños de Morelia', salieron de España con el consentimiento de sus familias, guiadas por el deseo de evitar a sus hijos las graves consecuencias de la guerra y aferrándose a la idea de que se trataría de una separación temporal7. Otra muestra de este interés tácito tuvo lugar un año más tarde, cuando se creó la Casa de España, posteriormente llamada El Colegio de México, a propuesta de Daniel Cosío Villegas 8 , con la intención de cobijar a figuras relevantes españolas de la academia, la ciencia y la investigación mientras llegaba el desenlace del enfrentamiento, con el objetivo de dotarles del ambiente y medios necesarios para que pudieran continuar su trabajo9.

En verano de 1939, con la llegada de los barcos procedentes de Europa, varios eran los problemas que México tenía que enfrentar para dar cabida a miles de personas. Uno de ellos era la distribución a lo largo y ancho de la República, con la idea de repoblar los estados del norte más deshabitados y con escasez de mano de obra ${ }^{10}$, como había prometido el presidente a la sociedad mexicana durante la

6 Para conocer más sobre las restricciones en el asilo de judíos en México, consultar los trabajos de Gleizer Salzman, Daniela: Unwelcome Exiles. Mexico and the Jewish Refugees from Nazism, 1933-1945, Boston, Brill, 2014; «México y el refugio judío. El mito de las puertas abiertas», en La memoria archivada. Los judíos en la configuración del México plural, unAM-FEs-Acatlán, 20II.

7 Son numerosas y variadas las publicaciones sobre estos menores exiliados, tanto de carácter académico como autobiográfico. Para un primer acercamiento al tema, consultar el libro de PlA BRUgat, Dolores: Los niños de Morelia. Un estudio sobre los primeros refugiados españoles en México, México, INAH, I999.

Daniel Cosío Villegas (I898-1976), economista, historiador, sociólogo, politólogo y ensayista mexicano. Fundó la editorial Fondo de Cultura Económica y fue presidente de El Colegio de México desde 1959 a 1962.

9 Sobre la historia de El Colegio de México, consultar los distintos trabajos de Clara E. Lida, entre ellos y junto a José A. Matesanz: El Colegio de México: una hazaña cultural, México, El Colegio de México, 1990.

ro Cárdenas diseñó una política de repoblación del país, pretendiendo que los españoles ocuparan la zona norte del territorio nacional, como Chihuahua, Coahuila o Durango. La creación de colonias 
LA COHESIÓN NACIONAL A TRAVÉS DE LA PRENSA ESCOLAR DE LOS COLEGIOS DEL EXILIO ESPAÑOL EN LA CIUDAD DE MÉXICO (I939-I960) SANDRA GARCÍA DE FEZ

campaña de sensibilización y apoyo a la causa republicana española. Los intentos por parte de las instituciones mexicanas obtuvieron escaso éxito, puesto que la mayor parte de los exiliados se concentraron en los núcleos urbanos más poblados, principalmente en la Ciudad de México ${ }^{\text {II }}$, atraídos por la idea de contar con mayores oportunidades laborales, de apoyo institucional y mutuo ${ }^{\mathrm{I2}}$. Resultaron infructuosos los esfuerzos de la administración mexicana por reubicarlos en los estados del norte.

El carácter de la emigración fue en buena medida familiar, como demuestran las cifras sistematizadas por Dolores Pla, quien afirma que los exiliados más jóvenes supusieron alrededor del $20 \%$ de la población total emigrada, lo cual representaría a 2.000 menores de quince años ${ }^{13}$, suma nada desdeñable que se fue incrementando durante los años cuarenta, con la llegada escalonada de más menores procedentes de la dura postguerra y de terceros países.

Tanto la concentración de población asilada en la capital como la llegada masiva de menores en edad escolar precipitaron la creación de los colegios, convirtiéndose en una de las caras más conocidas en la historiografía del exilio, tanto por su éxito empresarial como por el elevado número de menores españoles y también mexicanos que pasaron por sus aulas, y continúan haciéndolo hoy en día en dos de ellos: el Instituto Luis Vives y el Colegio Madrid. Por otro lado, con estas iniciativas se trataba de cubrir varios frentes abiertos con el arribo de refugiados como era la imperiosa necesidad de crear puestos de trabajo para los recién llegados, el completar el panorama de la oferta educativa de la ciudad y el de acallar las voces críticas contrarias a la campaña gubernamental de apoyo a los asilados políticos.

La afluencia intensiva de expatriados se produjo entre los años 1939 y 1942. En ese período, coincidente con la administración cardenista, uno de los ámbitos en

agrícolas fue una de las iniciativas de los organismos republicanos en el exilio que, con el auspicio del Gobierno mexicano, se llevaron a cabo sin el éxito esperado.

II Según datos de Clara E. Lida, entre 1939 y 1950, un 72.16\% de los exiliados optaron por vivir en la capital, siendo apenas un $4 \%$ los que radicaron en ciudades como Puebla, Morelia o Veracruz, distribuyéndose el resto por otras zonas del país. LidA, Clara E. (comp.) y GARCía Millé, Leonor: México y España en el primer franquismo, I939-1950. Rupturas formales, relaciones oficiosas, México, El Colegio de México, 200I, pp. 203-252.

${ }_{12}$ Por poner sólo un ejemplo de las condiciones de vida paupérrimas de los recién llegados, se toma el de Lorenzo Alcaraz, quien fuera uno de los fundadores de la Academia Hispano Mexicana, en cuyo expediente se recoge la demanda que hizo al Comité Técnico de Ayuda a los Republicanos Españoles, también conocido como Comité Técnico de Ayuda a los Refugiados Españoles (CTARE), de una ayuda económica: «Lorenzo Alcaraz Segura, se dirige consideradamente a ese Comité y le expone: Que se ha visto en la ineludible necesidad de abandonar el domicilio de Lucerna 65, para poder ocuparse, con la asiduidad que requiere, en la fundación de la Academia Hispano-Mexicana. Reside ahora en Uruguay, I64, donde habrá de pagar el correspondiente hospedaje. Carece, en términos absolutos, de todo recurso para atender esta obligación; pero, además, necesita comprar traje y ropa interior, que no tiene, con lo que se le hace imposible salir a la calle y mucho más realizar ciertas gestiones». Archivo del Comité Técnico de Ayuda a los Refugiados Españoles (CTARE) en Ciudad de México, Serie: auxilios, Sección: auxilios y Albergues, Expd. 6409.

${ }_{13}$ Pla Brugat, Dolores: Els exiliats catalans. Un estudio de la emigración republicana en México, México D. F., INAH y Orfeó Català, 1999, p. 159. 
los que más actuaciones legislativas y prácticas se llevaron a cabo fue el educativo. Como ya se ha dicho, instaurar una educación socialista pasaba, necesariamente, por construir las escuelas necesarias para que todo estudiante contara con una plaza escolar. Sin embargo, como recoge José Ignacio Cruz, a finales de su mandato continuaba existiendo el déficit de centros educativos, siendo especialmente grave el problema en la capital mexicana, debido a la mayor concentración de población ${ }^{14}$. Si se suma a este factor la importante representación de docentes hispanos desembarcados ${ }^{15}$, se tienen los elementos necesarios para entender cómo pudo llevarse a cabo tan rápidamente la puesta en marcha de las distintas escuelas. Sin embargo, fueron algo más que simples establecimientos educativos, ya que prestaban una serie de servicios subvencionados dirigidos a cubrir las múltiples carencias de los pequeños refugiados (becas escolares, servicio de comedor o atención sanitaria). De este modo, como sintetiza Monedero, los colegios tenían doble objetivo:

El primero era educar a los hijos de tal manera que no perdieran la identidad española, que se movieran entre gente similar a ellos y que la escuela inculcara en ellos el profundo republicanismo que aquellos hombres y mujeres habían defendido hasta las últimas consecuencias; el segundo era ofrecer a los muchos maestros que habían llegado, un empleo digno que les permitiera ir saliendo adelante, pues entonces todos eran pobres y lo único con que contaban era con su fuerza de trabajo ${ }^{16}$.

Así pues y en palabras de Alba M. ${ }^{a}$ Pastor, estos nuevos centros trataban de dar una imagen cohesionada del destierro frente a la sociedad y la clase política mexicanas, en un intento de mantener un perfil positivo y de entendimiento interno que alejara los temores de algunos sectores ${ }^{17}$ ante la presunta avalancha de republicanos exaltados y altamente politizados: «La función de estos colegios es, además de transmitir la ideología liberal republicana y su sistema de valores, mantener la cohesión del grupo, ya sea para el posible retorno o para amortiguar los problemas de una brusca adaptación, en caso de permanecer en América» ${ }^{18}$.

Conviene resaltar que la idea de fundar las instituciones educativas ya estaba en la mente de los refugiados antes incluso de pisar tierra mexicana por primera

${ }^{14}$ Cruz Orozco, José Ignacio: «Los colegios del exilio. La obra educativa de los maestros y profesores valencianos», en Girona Albuixech, Albert y Mancebo Peset, M. ${ }^{a}$ Fernanda (eds.): El exilio valenciano en América. Obra y memoria, Valencia, Universitat de València, 1995, p. 96.

is Pese a las facilidades prestadas por los gobiernos mexicanos, no siempre fue fácil el ejercicio de la docencia de forma legal. Para conocer más sobre el tema consultar: GARCíA DE Fez, Sandra: «La revalidación de los estudios de los maestros republicanos españoles exiliados en México (1939-1945)", Laberintos. Revista de la Biblioteca Valenciana, Valencia, 8-9 (2007), pp. 133-154.

${ }_{16}$ Monedero López, Enrique: Los colegios del exilio, Madrid, Cuadernos de la Fundación Españoles en el Mundo, 1996, p. r.

${ }_{17}$ Los sectores contrarios a la acogida de los exiliados españoles procedían tanto de la derecha mexicana más conservadora, como desde colectivos de izquierda que veían en los recién llegados una nueva remesa de conquistadores a imagen de Hernán Cortés.

18 Pastor Llaneza, M. ${ }^{a}$ Alba: Los recuerdos de nuestra niñez. Cincuenta años del Colegio Madrid, México, Colegio Madrid A. C., I991, p. I2. 
LA COHESIÓN NACIONAL A TRAVÉS DE LA PRENSA ESCOLAR DE LOS COLEGIOS DEL EXILIO ESPAÑOL EN LA CIUDAD DE MÉXICO (I939-I960) SANDRA GARCÍA DE FEZ

vez. En el diario de a bordo del barco Sinaia, se recogen referencias claras que permiten aseverar dicha afirmación, como la convocatoria a una reunión a los profesores que viajaban en el barco para tratar el tema de su futuro laboral en México's.

Ahora bien, los organismos republicanos de ayuda fueron estrictos en el cumplimiento del mandato presidencial de no disputar espacios laborales con mexicanos y en ningún momento se plantearon una línea de integración de los docentes españoles en el sistema educativo nacional. Esto no fue óbice para que algunos de ellos, atendiendo ofertas públicas, terminaran ejerciendo el magisterio en centros de distintos niveles, especialmente de estudios superiores.

Cada uno de los colegios tuvo un inicio y trayectoria disímiles que enmarcan y explican el carácter de sus publicaciones escolares; sin embargo, el origen hispano actuaba de nexo común, así como la pretensión de retornar, como recoge Julia Tuñón: «Los padres los inscribían [a los menores] en esos colegios pensando en el regreso a España, porque se sentían más cómodos $»^{20}$.

El primer centro en ser creado fue el Instituto Luis Vives, en agosto de I939, en plena llegada de las expediciones de acogidos a México. A iniciativa del Servicio de Evacuación de Republicanos Españoles (SERE), José Puche ${ }^{21}$ dio el visto bueno a la puesta en marcha del instituto, el cual ofrecía inicialmente estudios de primaria para, poco tiempo después, incorporar también los de secundaria. Al inicio se organizaron conferencias y clases de regulación de nivel, para reforzar a los estudiantes que, tras los años de guerra y el periplo de la emigración, habían sufrido importantes vacíos y atrasos en su formación.

Se inició el curso oficialmente en 1940 con una matrícula de cerca del centenar de niños y niñas, en su inmensa mayoría españoles. Económicamente el instituto dependía en sus primeros años de colectivos como el Comité Técnico de Ayuda a los Republicanos Españoles, también conocido como el Comité Técnico de Ayuda a los Refugiados Españoles (CTARE); la Sociedad Religiosa de Amigos -cuáqueros norteamericanos simpatizantes con la causa-, y de beneficiarios particulares. La progresión del instituto experimentó subidas y bajadas en su censo, pero siempre manteniendo unas dimensiones reducidas y un marcado carácter republicano y español, como continúa sucediendo en la actualidad.

Unos meses más tarde, en diciembre de 1939, el Instituto Hispano Mexicano Ruiz de Alarcón se presentó en los círculos de los expatriados brindando clases de formación media y superior. De capital mexicano mayoritariamente, el instituto, en su corta trayectoria de cuatro años, fue impulsado por el matrimonio formado por los educadores gallegos Pedro Martul Rey y M. ${ }^{a}$ de los Ángeles Tobío Fernández. Con mil estudiantes matriculados, establecieron dos espacios físicos diferenciados por sexos -excepción dentro de los centros españoles que fueron

19 Serrano Migallón, Fernando: op. cit., p. 53.

${ }_{20}$ Tuñón, Julia: Educación y exilio español en México. El Instituto Luis vives, 1939-2010, México D. F., INAH, 2OI4, p. II4.

${ }^{21}$ José Puche Álvarez, científico español y exrector de la Universidad de Valencia, miembro destacado del exilio español y representante del sere en México. 
mixtos teniendo en la coeducación una seña de identidad-, con una oferta académica diversificada. El apoyo de importantes personajes de la política nacional, entre ellos el propio presidente Cárdenas, favoreció el impulso a esta sociedad educativa, lo que no frenó su cierre en 1943 tras una época con importantes problemas de financiación y funcionamiento que hicieron insostenible prolongar su actividad $^{22}$.

En el mismo lapso de tiempo de finales de $1939^{23}$, surge en el panorama de la educación privada de la capital y a iniciativa de la Junta de Cultura Española el tercer centro: la Academia Hispano Mexicana. Encabezada por los matemáticos y profesores españoles Ricardo Vinós Santos y Lorenzo Alcaraz, los dos fueron depositarios de unos préstamos del SERE para dar forma a un nuevo establecimiento que abrió sus puertas con una matrícula de unos doscientos jóvenes en estudios de educación media y superior, en régimen de internado o externado, entre los cuales se encontraban hijos de políticos e intelectuales mexicanos cercanos a las propuestas republicanas. Unos años más tarde, el incremento de alumnado fue notable, ascendiendo a novecientos con la incorporación de clases de primaria a petición de las propias familias. La Academia ha sido el centro con menor identificación y vinculación al mundo del exilio, debido, especialmente, a la presencia mayoritaria de mexicanos y mexicanas entre el alumnado y el profesorado desde sus comienzos y a su independencia económica de los círculos del exilio. El gran prestigio académico con el que contaba contribuyó a la rápida y sólida integración en el país de acogida y a su mantenimiento en activo hasta el 2006, año en que cesó su actividad.

Para completar la oferta escolar y con los problemas del Instituto Ruiz de Alarcón como justificación, en I94I la Junta de Auxilio a los Republicanos Españoles (JARE) instituyó y mantuvo con fondos propios el Colegio Madrid. El centro en sus primeros cursos ofertaba primaria superando las novecientas plazas escolares, cubriendo los gastos escolares, alimentarios y sanitarios del alumnado. Jesús Revaque Garea fue el fundador y director del centro hasta 197I, dejando una significativa impronta en el carácter hispano de la escuela que, junto al citado Vives, continúa funcionando actualmente, ofreciendo todos los niveles educativos a excepción de la formación superior. El Madrid, como se conoce popularmente, nació con vocación de ser un centro grande, aumentando la matrícula básicamente entre las familias españolas refugiadas, aunque siempre contó con una minoritaria presencia de niños y jóvenes mexicanos que fue incrementándose con el paso del tiempo. El periódico que editaron, al igual que en las otras escuelas, es una clara muestra de la compleja convivencia de dos identidades nacionales, presente en las publicaciones que se analizan a continuación.

22 Para saber más sobre el Ruiz de Alarcón, consultar: GARCía DE FEZ, Sandra: «Una escuela desconocida del exilio: la polémica en torno al Instituto hispano Mexicano Ruiz de Alarcón», Educació i història: Revista d'història de l'educació, Barcelona, I7 (20II), pp. 213-235.

${ }_{23}$ Si bien se da de alta como centro educativo en septiembre de 1939, no es hasta febrero de I940 cuando se inician las clases de forma regular, tras unos meses de incorporación paulatina de los alumnos y alumnas a las clases de repaso y nivelación. 
LA COHESIÓN NACIONAL A TRAVÉS DE LA PRENSA ESCOLAR DE LOS COLEGIOS DEL EXILIO ESPAÑOL EN LA CIUDAD DE MÉXICO (I939-I960)

SANDRA GARCÍA DE FEZ

\section{Los periódicos escolares de los «colegios del exilio» y su función cohesionadora}

Los estudiantes de los centros españoles de la capital mexicana lograron que cada uno de ellos contara con su propia revista, volcando esfuerzos e intereses para dar continuidad a la iniciativa y lograr mayor implicación por parte de sus compañeros y compañeras. En los cuatro centros educativos, en mayor o menor medida, se conmemoraban no solo las fechas señaladas en la memoria republicana española, sino también en la mexicana, contribuyendo este hecho a la coexistencia entre ambas realidades identitarias. Siguiendo la idea de M. ${ }^{a}$ del Mar del Pozo, estos actos son: «Las fuentes más valiosas para explorar la construcción de la identidad nacional, ya que, según Hobsbawm, la mayoría de las veces en las que las personas toman conciencia de su pertenencia a una nación es por su participación en rituales y prácticas simbólicas» ${ }^{24}$.

Estas prácticas tenían su espacio también en los periódicos escolares, teniendo como antecedente las numerosas iniciativas editoriales realizadas por sus mayores:

Además de las razones económicas, se explica [la creación de editoriales en México] por la necesidad que sentían de compensar el alejamiento de su patria y la pérdida de su trabajo, bienes, personas e ideales, con lo que les parecía más duradero y susceptible de presentar una continuidad con el pasado. El universo mental de su cultura fueron los libros, las revistas, la escritura y la palabra y para ello la infraestructura material que los posibilitaba: editoriales, imprentas, redes de distribución y comerciales ${ }^{25}$.

Las publicaciones constituyeron una herramienta apropiada para conseguir un doble objetivo: convertir a los más jóvenes en observadores del contexto dentro y fuera de la escuela y respaldar la legalidad republicana en el destierro. La localización y consulta de las cuatro revistas no ha resultado una tarea sencilla, especialmente en el caso de los dos centros desaparecidos: el Instituto Ruiz de Alarcón y la Academia Hispano Mexicana. A excepción del Colegio Madrid que guarda en su biblioteca la colección casi completa de la revista Nosotros (I956I963), del resto de publicaciones se ha tenido acceso a números sueltos y en ocasiones fragmentados, considerados, sin embargo, suficientes para realizar el rastreo de la presencia de España en sus números.

Continuando con el orden cronológico de aparición de los colegios, los comienzos del boletín del Instituto Luis Vives fueron poco pacíficos. En i944 vio la luz la primera revista, llamada Terremoto, coordinada por un profesor mexicano de Geografía e Historia y Civismo, Vidal Luna Peralta ${ }^{26}$. En esta primera publicación,

24 Pozo Andrés, María del Mar del: «Presentación. Educación y construcción de las ideas nacionales», Historia de la Educación. Revista Interuniversitaria, Salamanca, 27 (2008), p. 28.

${ }_{25}$ Mancebo, María Fernanda: La España de los exilios. Un mensaje para el siglo XXI, Valencia, PUV, 2008, p. 246.

${ }^{26}$ Para esta asignatura, la legislación educativa del país obligaba a los centros extranjeros a contratar a profesorado mexicano, como es este caso. 
los alumnos más críticos vertieron comentarios y calificaciones poco positivas sobre parte del claustro, lo que provocó el malestar del director Rubén Landa ${ }^{27}$ y la consiguiente clausura del periódico. El enfrentamiento entre estudiantes y docentes derivó en el abandono por parte de Vidal Peralta de su plaza docente, provocando con ello una convocatoria de huelga entre los jóvenes. El motín se solucionó con la intervención de las familias que forzaron el regreso a las aulas ${ }^{28}$. Poco tiempo después, se retomó la publicación cambiando el nombre por el de Retorno, bajo la supervisión de la profesora Ángela Campos ${ }^{29}$, apareciendo regularmente hasta 1947 cuando dejó de editarse ${ }^{30}$. Durante un breve lapso de tiempo, entre 1946 y 1947, convivieron dicha revista y otra de nueva aparición: Eureka.

En los cuatro números hallados de Eureka correspondientes a los meses de febrero, marzo, mayo y junio de 1947 , se da tribuna a la polémica entre los equipos editoriales de ambas publicaciones y el acuerdo al que se llegó para imprimir un único medio. En el número i4 de Eureka se hacía referencia a estos intentos de unión: «El "Retorno" que todos recordarán, dejó de salir el año pasado, pero sus dirigentes nunca perdieron la esperanza de volverlo a publicar, y este curso, decidieron, junto con nosotros, que nos uniéramos para continuarlo, fundiéndolo con el nuestro» ${ }^{3 \mathrm{I}}$.

A pesar de la tentativa, la unificación de los dos periódicos tuvo una andadura muy breve. Si bien al mes siguiente se presentaba el primer número fruto de los acuerdos tomados, la ruptura fue palpable en el ejemplar correspondiente a mayo, donde el grado de politización de estos jóvenes queda patente: «Si los partidos políticos, si las grandes naciones, hiciesen este pequeño gesto, dejando a un lado los intereses prácticos de las cosas, cuantas guerras, y cuantas luchas intestinas se hubiesen evitado, y también cuantas victorias se hubiesen ganado» ${ }^{32}$.

El tono editorialista supone una dura crítica al grupo promotor de Retorno, como se puede comprobar a continuación,

La unión entre el «Eureka» y el «Retorno» existente desde el número anterior ha sido deshecha como todos saben [...] ¿Motivo? Su tradición. Su periódico tenía una tradición de varios años que ha hecho exaltar su «patriotismo» y han decidido volver a publicar el tan popular «Retorno». A nosotros nos ha parecido bien, excelente; solo que hayamos una falta imperdonable: el que hayan realizado la unión ${ }^{33}$.

27 Rubén Landa Vaz (1890-1978), abogado y educador de origen extremeño, con gran vinculación a la Institución Libre de Enseñanza.

${ }_{28}$ Morán, Beatriz y Perujo, José A.: Instituto Luis Vives. Colegio Español de México. 19391989, México, Embajada de España en México, 1989, p. 20.

${ }_{29}$ Ángela Campos Arteaga, maestra española participante en las Misiones Pedagógicas, ejerció en el Vives como docente desde su llegada a México.

30 No ha sido posible encontrar ningún ejemplar de Terremoto ni de Retorno por lo que la revista que se analiza es Eureka. De estas publicaciones se tienen referencias de fuentes secundarias y testimonios de exalumnos.

${ }^{31}$ «Editorial», Eureka, febrero de 1947, núm. I4, p. 2.

32 «Editorial», Eureka, marzo de 1947, núm. I5, p. 2.

33 «Editorial», Eureka, mayo de I947, núm. 16, p. 2. Entrecomillado en el original. 
De este fragmento nos interesa destacar la palabra entrecomillada "patriotismo», por la clara referencia a España que supone y, más concretamente, a una velada acusación de falta de españolidad y de fidelidad a la causa de la nueva revista y sus creadores. Las secciones del periódico recogían los trabajos presentados por los editorialistas y el resto de estudiantes que participaban, perteneciendo a secundaria mayoritariamente. En la primera página de Eureka, convivían la editorial y una sección denominada «Kaleidoscopio», compuesta por breves apuntes a modo de notas jocosas, avisos o comentarios de la vida cotidiana del instituto. El siguiente apartado, «La ensalada rusa», firmada por Miguel Ángel Galarza, ejercía de muestra de los asuntos más relevantes entre el estudiantado: festejos entre novios y anécdotas de la vida escolar, copando la mayor atención de la redacción de la revista.

El resto de páginas hasta un total de 12 o I6, según los números, son una compilación de artículos, poemas, chistes y crónicas deportivas, realizados por el equipo de redactores. De las colaboraciones externas cabe destacar la de José Palma apostillado como un 'Corresponsal exclusivo de Eureka en Tanger [sic]' o a 'control remoto'34, ya que lo hacía en calidad de exalumno e informaba desde Marruecos, su lugar de residencia tras haber vivido en México.

Las referencias al origen español de los alumnos y el destierro como contexto vital son argumentos recurrentes en muchas de las aportaciones que se recogen en la publicación. Así, en el número catorce Montserrat Cid escribió un texto llamado «El Ebro». La referencia casi obligada a la Guerra Civil española la hace en los siguientes términos:

En el Ebro fué donde, durante la guerra civil española, se dió una de las más terribles batallas. De un lado se encontraban los franquistas y del otro los republicanos. Cada uno de los bandos trataba de atravesar el Ebro cuyos puentes habían sido volados, para lo cual necesitaban construir puentes de barcas que la corriente se llevaba y cuando se tenía el puente, había que desafiar las balas del enemigo ${ }^{35}$.

Resulta inverosímil que ella pudiera vivir en primera persona los hechos que describe, por lo que se puede inferir que repite un episodio leído o escuchado y que le resulta tan familiar como para poder describirlo con nitidez e intensidad. Finaliza repitiendo el deseo nostálgico oído tantas veces: la vuelta a la patria: «Pero aunque el Ebro traiga a mi mente recuerdos tristes, sólo espero el momento en que mis ojos vuelvan a contemplar su curso amado» ${ }^{36}$. En la misma línea, en un escrito de corte literario, Alberto Oliart recuerda un episodio de su vida en España siendo muy pequeño. Recrea una excursión al campo junto a su amigo Antonio, de mayor edad y voluntario posteriormente en la defensa republicana y luchador en el frente de Aragón. Al hablar sobre su separación lo hace desde el anhelo del

34 «Editorial», Eureka, marzo de 1947, núm. I5, p. I6.

35 Cid, Montserrat: «El Ebro», Eureka, febrero de I947, núm. I4, p. 9.

36 CiD, Montserrat: «El Ebro», Eureka, febrero de 1947, núm. I4, p. 9. 
regreso: «A veces pienso que fuiste para mí un tercer hermano. ¿Cuando [sic] dejará de separarnos este mar cruel?» ${ }^{37}$.

A pesar de la juventud de los escritores son muchas las referencias a sentimientos, anhelos y recuerdos mitificados sobre el país de origen, siendo fieles a todo aquello que perciben y viven tanto en el ámbito familiar como en la escuela y en el mundo endogámico de los emigrados. Salpican las páginas de la revista numerosas referencias patrióticas, así como a los literatos y pensadores ligados a la Segunda República, como, por ejemplo, Antonio Machado. La cultura popular también cuenta con su espacio: chistes sobre catalanes, coplillas sobre los andaluces o canciones de las distintas regiones de la península. No resulta extraño que estas publicaciones puedan ser consideradas como la voz del colectivo español en boca de las nuevas generaciones, con la clara intencionalidad de mantener la unión de grupo, las expectativas de regreso y, en definitiva, la lucha por la legitimidad del Gobierno republicano en el exilio.

Por su parte, el Instituto Hispano Mexicano Ruiz de Alarcón también tuvo su propia revista: Senda, de la cual se ha podido examinar un número incompleto correspondiente a 194I. En este ejemplar se explica cómo surge la publicación a iniciativa de un seminario de estudios de alumnos, espacio de reunión para fomentar la autoformación cultural y el intercambio de conocimientos, con la intención de dar a conocer al resto de la comunidad escolar el fruto de ese trabajo colectivo. Este espacio formativo era descrito como una «escuela autónoma donde todos nosotros podamos estudiar con mayor profundidad los temas de las diferentes materias que hayan sido explicados en las clases y también los que expontáneamente [sic] sean propuestos por nosotros mismos» ${ }^{38}$.

Pese a desconocerse los datos básicos de la publicación como periodicidad y números impresos, se puede deducir el carácter de la revista: formal, metódico y centrado en la vida académica y en los actos protocolarios del centro, como muestran las fotografías de un homenaje al profesorado o la celebración de la Fiesta de la Raza ${ }^{39}$. Entre los artículos que daban cuerpo al periódico, Antonio Castro Lea ${ }^{40}$ realiza una breve referencia sobre el dramaturgo Juan Ruiz de Alarcón, personaje que le da nombre al centro y que sirve de excusa para subrayar las relaciones entre España y México a través de su figura:

[Juan Ruiz de Alarcón] nace en México y muere en España; fué bachiller por Salamanca y licenciado por México; se puso el don por los Alarcones de Cuenca y los de Taxco, por los Mendozas del reino y por el virreinato. No pudo acomodarse en el país de su nacimiento y se fué a España, en donde siempre lo tuvieron por extraño, si no por extranjero ${ }^{41}$.

Oliart, Alberto: «¿Recuerdas?», Eureka, febrero de 1947, núm. I4, p. IO.

«Nuestro Seminario de Estudios», Senda, I94I, p. 7.

39 Es la conmemoración del I2 de octubre de I492, llegada de Cristóbal Colón a tierras americanas.

40 Antonio Castro Leal fue un abogado y escritor mexicano que llegó a ser rector de la Universidad Nacional Autónoma de México (UNAM) entre 1928 y 1929. Mantuvo un fuerte compromiso con los refugiados españoles en México.

${ }^{41}$ Castro Leal, Antonio: «Ingenio y sabiduría de D. Juan Ruiz de Alarcón», Senda, 194I, p. 2. 
De estos apuntes biográficos, resulta interesante destacar el doble origen del personaje y las dificultades identitarias que conlleva nacer en un lugar y residir en otro. Se trata de una descripción aproximada de lo que experimentaron a lo largo de sus vidas miles de refugiados españoles, al entender la identidad nacional como un proceso variable y problemático.

En las siguientes páginas destaca un trabajo titulado «La Poetisa Gallega Rosalía de Castro». En el texto dedicado a la escritora -máxima representante del galleguismo cultural del siglo XIX-42 es clara la referencia a España y a la identidad regional gallega: «Años después, en 1902, al formar D. Juan Valera sus deplorables "Florilegio de Poesías Castellanas del siglo XIX", no incluyó a nuestra poetisa más que de pasada y concediéndole menos categoría que a los autores anónimos y a los poetastros insignificantes» ${ }^{43}$. El pronombre utilizado denota un fuerte sentimiento de pertenencia regional y exaltación de la cultura gallega. En todo caso, el periódico Senda se presentaba al lector con un marcado carácter académico y alejado de las publicaciones del Instituto Luis Vives mucho más juveniles e informales, tanto en su estética como en sus contenidos. Era fiel reflejo de la idiosincrasia del Instituto, distanciado de los organismos oficiales españoles e implantado en la realidad mexicana, aunque con continuos guiños al origen español.

Continuando con el repaso a las publicaciones, la Academia Hispano Mexicana, por su parte, editó a finales de los años cincuenta AHMbiente, nombre formado con el acrónimo de las siglas de la Academia, AHM, alterando la palabra ambiente, muestra del ingenio de la sociedad de alumnos promotores de la revista. Se aprecia una importante presencia de México en los tres ejemplares a los que se ha tenido acceso de los años 1958 y 1959. Tanto por los temas elegidos como por los giros lingüísticos y los modismos mexicanos utilizados, permite afirmar que la publicación se alejaba de lo español como referente. Este hecho resulta plenamente justificable en cuanto a la mayoritaria presencia de alumnado y profesorado oriundo de México, así como el inexorable paso del tiempo, ya que aparece con quince años de diferencia con las publicaciones anteriores y, por lo tanto, con el centro educativo arraigado a la capital mexicana.

La vida escolar y los aspectos más jocosos, los encuentros deportivos, así como textos literarios de creación propia, ocupan la mayor parte de las hojas de la revista. Pese a ello, el interés por la geopolítica internacional se plasmaba en algunas de las secciones del periódico. De hecho, en la editorial del primer número, se sintetizaba la situación mundial y se profundizaba en los motivos por los cuales las personas que conformaban el centro, y en especial el estudiantado, deberían interesarse por temas como las guerras, la discriminación racial en Estados Unidos de América o la pobreza en los países africanos: «Por otra parte tienes que ver que el perjudicado más directo por todos esos problemas vas a ser tú mismo. Por

${ }_{42}$ Cabe recordar que buena parte del claustro estaba formado por profesorado de origen gallego, encabezado por el matrimonio de directores fundadores del mismo.

43 «La Poetisa Gallega Rosalía de Castro», Senda, I941, p. 19. El subrayado es nuestro. 
ejemplo, si hubiese una III Guerra Mundial ¿quién sería el más afectado, sino la juventud que iría a ella, y todas las generaciones venideras?» ${ }^{44}$.

La llamada a la politización y a tener una postura propia y razonada ante los acontecimientos mundiales del momento es una muestra más de cómo los estudiantes de la Academia no debían caer en la apatía social. Sin tratarse claramente de una invitación a la intervención en la política mexicana o española, esta dimensión internacionalista fue uno de los rasgos característicos del período que abrió España al extranjero durante los años de gobierno franquista y mantuvo lazos y apoyos durante su periplo en el destierro.

Son reiteradas las convocatorias a la contribución del resto de compañeros y compañeras en la publicación y en las actividades que desde la Sociedad de Alumnos desarrollaban, lo cual da pie a interpretar que la participación no era la deseada. Destaca entre sus iniciativas el buen funcionamiento del grupo de teatro experimental 'Minerva' -llamado así por el escudo del colegio que representa a la divinidad de las ciencias y la sabiduría-, consiguiendo que una sala de la Academia fuera habilitada para las representaciones teatrales. La estima y el fomento de la cultura y sus diferentes expresiones son una constante en esta revista, así como las referencias a autores españoles y vinculados con la Segunda República. Entrevistas a docentes españoles, una conferencia impartida por el pintor exiliado Arturo Souto ${ }^{45}$ y la publicación de cuentos y textos cortos ilustran esta aseveración. A lo largo de los distintos números, se mantuvo una sección de «Refranes hispánicos» en la cual los jóvenes, en forma de juego, compartían con sus compañeros algunos de los refranes más conocidos y utilizados por las familias hispanas ${ }^{46}$.

Las expresiones peninsulares conviven con las mexicanas. Un ejemplo es la invitación que hace el equipo de redacción a la colaboración con la revista, la cual inicia con un 'ea' muy español y con una referencia a la Patria que, al no especificarse, puede hacer referencia a la de origen o a la de acogida: «Ea pues, compañero, te esperamos con la firme convicción de que no defraudarás a tus amigos, a tu escuela, a tu Patria»47. Algunas otras referencias al país de nacimiento se intercalan en los diferentes números del periódico como la presentación de un texto llamado «El Trepanado» ${ }^{8}$, procedente de la histórica publicación satírica española La Codorniz ${ }^{49}$, lo cual permite inferir el seguimiento por parte de los jóvenes de lo que sucedía en el país de nacimiento.

Así mismo, México es una presencia continuada en los artículos publicados. Una carta escrita por Juan Luis Enríquez Alcázar titulada «A los estudiantes», relacionando la Revolución mexicana con el deber moral de los estudiantes para participar en los temas políticos y sociales del país, da muestra de ello:

44 «Editorial», AHmbiente, 1958, núm. 2, p. 3.

45 Arturo Souto Feijoo (1902-1964), pintor gallego de reconocido prestigio que, debido a su apoyo al Gobierno de la II República, tuvo que exiliarse una vez finalizada la Guerra Civil española, viviendo en distintos países, hasta que llegó a México en 1942.

${ }_{46}$ «Refranes Hispánicos», AHmbiente, I de junio de I959, p. I2.

47 «Editorial», AHMbiente, I de junio de I959, p. 3.

$4^{8}$ «El Trepanado», AHmbiente, I de junio de 1959, p. I6.

49 Revista española de humor gráfico y literario que se publicó desde I94I hasta I978. 
LA COHESIÓN NACIONAL A TRAVÉS DE LA PRENSA ESCOLAR DE LOS COLEGIOS DEL EXILIO ESPAÑOL EN LA CIUDAD DE MÉXICO (I939-I960) SANDRA GARCÍA DE FEZ

Cuando los héroes de la Patria se desentendieron del bienestar individual y ofrendaron hasta su vida, sabía que trabajaban para la posteridad, no para ellos. ¿Qué es el tiempo, la vida de un hombre, frente a la vida y el futuro de un pueblo? Los hombres pasan, más los pueblos perduran y la historia sigue imperturbable el ritmo indefinido del progreso. No olvidar esto y así estaremos seguros que lo mismo que hoy los honramos a ELLOs, mañana habrá hombres que nos honrarán a nosotros ${ }^{50}$.

Sorprende, por otro lado, la aportación del joven Carlos Camacho Kapellmann, ganador de retórica, la furibunda argumentación en contra del comunismo: «El comunismo con su tesis radicalmente socialista avanza gigantesco y monstruoso, y nosotros nos espantamos de que ya se sientan y se respiren sus aromas venenosos en nuestro México» ${ }^{5 \mathrm{I}}$. En ambos casos se trata de acercar la política al estudiantado de la Academia en un llamado a la implicación activa.

Por último, en el Colegio Madrid a partir de 1956, y coincidiendo en fechas con la Academia Hispano Mexicana, también se editó una publicación de nombre Nosotros con una periodicidad bimensual. Resulta entendible que la revista apareciera unos años después de la ampliación de la oferta escolar a secundaria y bachillerato en 1951. Estuvo editándose hasta noviembre de 1963, cuando pasó a denominarse Nosotros Abora. El carácter hispano del colegio tuvo su reflejo en la publicación escolar, donde los hechos históricos, fundamentalmente relacionados con su pasado más inmediato, ocupan buena parte de las secciones escritas a lo largo de los ocho cursos. La declaración de intenciones queda plasmada desde el primer número cuando se evoca la creación del Madrid, incidiendo en los elementos identitarios:

A fin de no crear nuevas dificultades al país que tan gentilmente abrió sus puertas a la emigración, comenzaron a formarse centros de enseñanza [...] La verdadera finalidad de este nombre [Colegio Madrid] es perpetuar la heroica epopeya de la defensa del pueblo madrileño durante los años I936-1939 $9^{52}$.

Aún más, se incide en el firme propósito de fomentar entre los escolares el amor a las dos patrias, educando a los niños y niñas en la fidelidad al país de origen y en la aceptación de la patria de acogida: «Otro deseo de la Dirección fué que la Escuela supiera conjugar el amor a España con el amor a México»\$3.

El carácter conciliador del centro educativo entre los dos contextos nacionales aparece reiterativamente en ilustraciones y fotografías, como las que recogen la celebración de la proclamación de la Segunda República en uno de los símbolos patrios mexicanos de mayor reconocimiento, con una nota al pie: «Los alumnos del Colegio Madrid ante la columna de la Independencia, conmemorando el

- EnríqueZ alcázar, Juan Luis: «A los estudiantes», aHmbiente, I de junio de 1959, p. 4.

st Camacho Kapellmann, Carlos: «Sección demagógica..??..», Ahmbiente, i de junio de I959, p. 8.

52 «Fundación del Colegio», Nosotros, febrero de 1956, núm. I, p. 5.

53 «Fundación del Colegio», Nosotros, febrero de 1956, núm. I, p. 5. 
I4 de abril» ${ }^{4}$. México aparece en buena parte de las secciones del periódico, como en las entrevistas a personajes relevantes, entre los que se encontraban el pintor Diego Rivera, junto a testimonios de españoles refugiados significativos como el político Indalecio Prieto o el poeta León Felipe. De nuevo la literatura retorna en forma de pequeñas biografías de Pío Baroja o Cervantes y en las reseñas y críticas a libros.

La política española también era objeto de reflexión entre los jóvenes ensayistas; de hecho, las alusiones a la sublevación franquista y a la posterior guerra son numerosas en los distintos números. Un ejemplo es el siguiente texto firmado como Darico por un alumno:

Muchos fueron los españoles que no quisieron seguir viviendo bajo el régimen de los traidores de la República al final de la guerra, y entonces México les ofreció un asilo y una nueva patria donde poder rehacer su vida. Nosotros sentimos vivamente el dolor de España; el dolor de la guerra y el de los años que han seguido llenos de miseria y oprobio. Y nunca olvidaremos el magnífico ejemplo de solidaridad que dio México al mundoss.

Es de destacar el tono casi místico del texto utilizando la primera persona del plural, queriendo dar a entender al potencial lector que el joven que escribe se siente parte activa de la lucha de los adultos en su defensa del legado republicano. Por otro lado, el país de acogida tenía su sección fija en «Nacional», donde se trataban temas como el Centenario de la Constitución de i857 a cargo de la alumna Ramona Compte ${ }^{56}$, la celebración de las Fiestas Patrias del is de septiembre ${ }^{57}$ o el recuerdo de la nacionalización del petróleo ${ }^{58}$, mostrados todos ellos desde un elevado sentimiento nacional de pertenencia, aparente o no, pero presente en la revista.

El interés por los sucesos internacionales ocurridos en la década de los 50 es la tónica en las revistas estudiadas de los cuatro centros. Tras el período vacacional escolar, en febrero del año 1957 Adolfo Martínez Palomo hizo llegar a Nosotros un texto dirigido a la sección «Mundial», en el cual daba su opinión sobre la Revolución húngara desarrollada en los meses de octubre y noviembre de 1956, destacando la heroicidad de «la rebelión del pueblo húngaro en contra del gobierno soviético» ${ }^{99}$. A continuación, daba paso a una fuerte crítica a la conformación de la Unión de Repúblicas Socialistas Soviéticas (URss) anexándose por la fuerza, en muchas ocasiones, los países conocidos como satélites. Ateniéndonos al perfil politizado de una parte sustancial del exilio y la importante representación

4 «Sección Gráfica», Nosotros, I4 de abril de 1956, núm. 2, pp. 6 y 7.

Darico: «El i8 de julio», Nosotros, agosto de i956, núm. 4, p. 5 .

56 Compte, Ramona: «Centenario de la Constitución de I857», Nosotros, febrero de 1957, núm. 6, p. 4 .

«Is de septiembre», Nosotros, octubre de 1958, núm. I3, p. 4.

58 «Nacionalización», Nosotros, octubre de i960, núm. I9, p. Iо.

59 Martínez Palomo, Adolfo: «Consideraciones sobre el mundo actual», Nosotros, febrero de 1957 , núm. 6, pp. 3 у 4. 
LA COHESIÓN NACIONAL A TRAVÉS DE LA PRENSA ESCOLAR DE LOS COLEGIOS DEL EXILIO ESPAÑOL EN LA CIUDAD DE MÉXICO (I939-I960)

SANDRA GARCÍA DE FEZ

de dirigentes y comunistas españoles en México $^{60}$, quienes contaron con la solidaridad del Partido Comunista Mexicano (PCM), llama la atención el evidente anticomunismo presente en estas líneas -al igual que ocurría por fechas similares en la publicación de la Academia-, donde se afirmaba sin tapujos que en Rusia imperaba una dictadura contraria a la libertad del pueblo.

Dos referencias más que reflejan el origen hispano del Colegio Madrid y de su comunidad educativa se encuentran en el reconocimiento al general Lázaro Cárdenas, punto de unión incuestionable entre los emigrantes españoles de distintas filiaciones políticas e ideológicas. Mariano García Viveros realizó una crónica del homenaje del exilio español a la figura del político, haciéndolo coincidir con el i4 de abril de i957. Una representación del colegio estuvo presente en la rueda de prensa previa y en el acto que contó con representantes del destierro como Manuel Martínez Feduchy -ministro de la República en el exilio-, Félix Gordón Ordás -quien fuera embajador español en México durante la guerra- o el arquitecto Bernardo Giner de los Ríos. Se desarrollaron una serie de intervenciones, entre ellas las del propio homenajeado, el expresidente Cárdenas. Lo que interesa acentuar es cómo refiere el acto el autor de la crónica:

Terminó su discurso [Lázaro Cárdenas] con unas palabras de aliento y de confianza para que la causa de la República española obtuviera un completo triunfo, derrotando al hombre que no debió de haber nacido. No hay palabras para explicar la actitud del público, que si no hubiera sido porque las notas del Himno Republicano Español fueron entonadas, hubiese continuado con los aplausos. Para finalizar, el Himno Mexicano despidió al hombre a quien todos nosotros debemos el orgullo de ser mexicanos ${ }^{61}$.

Sin embargo, no siempre la deseada cohesión entre el colectivo de expatriados era una realidad. De hecho, son sobradamente conocidas las disputas entre facciones políticas y sindicales, así como los escollos entre las distintas identidades regionales que tuvieron sus espacios propios en México ${ }^{62}$. En este sentido, en la sección de Exalumnos y firmada con el seudónimo de Diógenes, se hace una reseña completamente idealizada y mitificada de Cárdenas y de su política, acompañada de una férrea crítica a aquellos refugiados «que no son realmente republicanos», distinguiendo entre los que tienen una verdadera inclinación republicana y los que sólo la simularon para llegar a México:

- Yo creía que en México había más republicanos.

6o En una investigación no publicada del historiador Torres Mantecón, se cifra en unos 500 los miembros del Partido Comunista Español (PCE) llegados a México en las primeras expediciones de 1939: Torres Mantecón, Marco A.: «Comunistas españoles en México. Una primera aproximación a la historia del Partido Comunista de España en su exilio mexicano (1939-1977)». Trabajo presentado en el Seminario México-España de El Colegio de México el 28 de febrero de 2007.

${ }_{61}$ García Viveros, Mariano: «Homenaje al General Lázaro Cárdenas», Nosotros, mayo de I957, núm. 7, p. 9.

${ }_{62}$ Nos referimos a centros regionales, algunos de ellos existentes previamente, en los cuales algunos refugiados encontraron un lugar de encuentro y apoyo, por ejemplo, el Orfeó Català. 
- No. No hay más republicanos. Lo que pasa es que tú estás confundiendo a los republicanos con los refugiados. Refugiados hay más.

- ¿Pero no viene a ser lo mismo?

- No. Hubo muchos que se equivocaron de lado, que vinieron al exilio por un error. Son los que por necesidad se hicieron pasar por liberales, pero que aquí han dado rienda suelta a sus instintos, y se han convertido en nuevos encomenderos. Esos refugiados no son republicanos... no son liberales [...] Para todos ellos, para los que sólo piensan en conseguir el suficiente dinero para poder volver a España a darse una vida "padre», don Lázaro sigue siendo «ese tal Cárdenas»; mientras que para los verdaderos republicanos, para los que han encontrado en México una segunda patria, para los que saben lo que es agradecimiento, ya no es el expresidente de un país que les prestó ayuda, sino que es el gran «Tata Lázaro», admirado y querido, no sólo por ellos, sino también por su pueblo, por los buenos mexicanos ${ }^{63}$.

Se asegura por parte del autor anónimo que existen distintos niveles de compromiso político entre los emigrados y, por lo tanto, diferentes categorías, lo que difiere enormemente de la idea de cohesión y solidaridad del colectivo que se pretendía ofrecer públicamente.

Además, el seguimiento de la vida escolar era, como en el resto de periódicos, una parte importante de las hojas del Nosotros, en las que se daba cuenta de acontecimientos deportivos, fiestas, graduaciones y actividades culturales, temas que conformaban la vida cotidiana en el centro y ayudaba a distender la publicación cargada de elementos políticos.

\section{A modo de conclusión}

La escritura, tanto individual como colectiva en forma de boletines, revistas y periódicos, desempeñaba un papel fundamental antes del triunfo de la República en las urnas, durante sus años de gobierno y posteriormente, en la defensa y reivindicación de su papel histórico en la vida española. Mantener lazos, conexiones y unos objetivos generales comunes dentro del colectivo de exiliados en México y en otros países se volvió una necesidad para miles de españoles y españolas que vivían con la vista puesta en un posible regreso a la patria abandonada por cuestiones ajenas a su voluntad.

Las publicaciones escolares no fueron una excepción en esta tendencia marcada por los progenitores. Jóvenes españoles y mexicanos, alumnos de unos centros creados por y para los refugiados y simpatizantes de la causa republicana, plasmaban, mediante artículos, creaciones literarias o crónicas, el día a día escolar en México y los recuerdos del pasado y las expectativas sobre el futuro anhelado en España. Ambos países fueron claros referentes en la vida académica y social de los centros, con algunas diferencias como ha quedado

${ }_{63}$ Diógenes: «El Tonel», Nosotros, mayo de 1957, núm. 7, p. I4. 
reflejado en el estudio de las publicaciones, ligadas al carácter y visión de cada escuela. Un aspecto común destaca sobre otros: el valor del grupo como agente dinamizador de la vida escolar, social, política e identitaria. Los centenares de hojas escritas por los estudiantes españoles permiten un primer acercamiento a la compleja dinámica interna de unos colegios que, desde sus comienzos, navegaron en muchos niveles entre dos referentes identitarios: México y España.

La premisa de mantenerse unidos como colectivo pese a las diferencias y, en ocasiones, irreconciliables disputas hizo que una buena parte de los exiliados realizara denodados esfuerzos para mantener viva la llama republicana y ésta fuera transmitida a las nuevas generaciones portadoras de la historia y del compromiso político. Las revistas hicieron propia esta responsabilidad sin menoscabar la presencia de México en sus páginas, patria que finalmente fue ganando terreno y afecto entre quienes echaron raíces en él sin retirar totalmente la mirada del otro lado del Atlántico. 